\title{
An Effective Hybrid Sine Cosine Algorithm to Minimize Carbon Emission on Flow-shop Scheduling Sequence Dependent Setup
}

\author{
Dana Marsetiya Utama \\ Department Industrial Engineering, Universitas Muhammadiyah Malang, Indonesia \\ Jalan Raya Tlogomas No. 246, Malang 65144, Indonesia \\ Corresponding author: dana@umm.ac.id
}

\section{ARTICLE INFO}

\section{Article history}

Received August 19, 2018

Revised January 5, 2018

Accepted February 20, 2019

Available Online February 28, 2019

Keywords

Emissions

Sine Cosine

flow shop

Scheduling

\begin{abstract}
Recently, carbon emissions have become a major environmental problem. In the industrial sector, carbon emissions account for half of the world's total carbon emissions. This article discusses the issue of scheduling Flow Shop Sequence Dependent Setup (FSSDS). It aims to minimize carbon emissions. The algorithm proposed is the Hybrid Sine Cosine Algorithm (HSCA) to solve FSSDS problems to reduce carbon emissions. We offered one of some search agents in the SCA using NEH. The algorithm is used for some tests on different jobs and machines. Several experiments were carried out to test the parameters and effectiveness of the algorithm. The parameters used in the trial are population and iteration. As a result, several parameters were proposed to HSCA to minimize carbon emissions. In the effectiveness test, the HSCA showed better performance compared to the simulated annealing and cross-entropy algorithm.
\end{abstract}

This is an open-access article under the CC-BY-SA license.

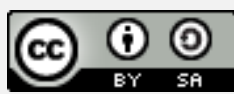

\section{Introduction}

Recently, global warming and increasing carbon emissions have become major environmental problems. The industrial sector accounts for half of the world's total carbon emissions [1]. The energy consumption of this sector has almost doubled over the past 60 years [2]. The increase in carbon emissions raises concerns related to climate change. Manufacturing companies face pressure to reduce carbon emissions. Environmental and economic factors motivate to reduce energy consumption and emissions from manufacturing companies [3-5]. At present, the problem of minimizing energy consumption and emissions is the focus of researchers. One effective way is scheduling. Proper scheduling can minimize carbon emissions. Scheduling is the arrangement of resources to carry out many jobs at a particular time $[6,7]$. Generally, some jobs are produced in the same process sequence [8]. These problems are categorized as Flow Shop 
Scheduling Problem (FSSP). Generally, FSSP aims to complete jobs to minimize completion time [8]. Flow Shop Sequence Dependent Setup (FSSDS) is an FSSP development problem. In FSSDS, the machine setup time is dependent on the machine sequence. In this problem, the order of jobs affects the setup time [9].

In the flow shop problem, some procedures are examined by researchers. Heuristic algorithms that are popularly used in the case of flow shops are Campble Dudek Smith (CDS) [10], Branch and bound [11], and Nawaz Encore Ham (NEH) [12]. Furthermore, several metaheuristic algorithms that are often used are simulated annealing [13,14] and the immune system algorithm [15]. Some researchers have also examined the problems of flow shop blocking [16], flow shop with maintenance activities [17]. Furthermore, Riahi, et al. [18] examined the flow shop problem with search spread. Karimi and Davoudpour [19] proposed a competitive colonial algorithm for the multi-objective Hybrid flow shop problem. Hatami, et al. [20] used the colonial competitive algorithm for the flow shop problem with the initial setup time. Generally, researchers use the minimization completion time performance.

At present, research minimizing energy and carbon emissions has not been much studied. However, several researchers have studied this problem. Utama [21]proposed the CDS and NEH algorithm to minimize energy consumption. Liu, et al. [22] proposed a hybrid fruit fly algorithm for solving flexible job-shop to maximize carbon footprint. Zeng, et al. [23] proposed the NSGA II algorithm to minimize energy consumption. Tang, et al. [24] proposed the PSO algorithm to minimize carbon emissions. Piroozfard, et al. [25] proposed minimizing carbon emissions using the Genetic algorithm. Li, et al. [26] used a hybrid optimization approach to minimize carbon emissions. Wu and Che [27] proposed minimizing carbon emissions in parallel machines using the Memetic Differential Evolution algorithm. Batista Abikarram, et al. [28] conducted minimizing carbon emissions in parallel machines. Tan, et al. [29] proposed scheduling to minimize carbon emissions with MILP.

The above review shows that several studies have been conducted. However, to our knowledge, no researchers have used Sine Cosine Algorithm (SCA) to minimize carbon emissions. Therefore, this study aims to develop a new algorithm to solve the FSSDS problem. We propose the Sine Cosine Algorithm (HSCA) hybrid algorithm to solve this problem. The proposed algorithm is used to minimize carbon emissions in the FSSDS problem. The Sine-cosine (SCA) algorithm is an optimization algorithm proposed by Mirjalili [30]. The SCA algorithm refers to the No Free Lunch (NFL) theorem. The NFL theorem allows researchers to propose new algorithms or improve current procedures. This algorithm can be used to solve problems in different fields. This SCA algorithm is based on the cosine sine of mathematical functions to solve optimization problems.

\section{Methods}

\subsection{Nomenclature and Problem Definition}

The problem of scheduling the Flow Shop Sequence Dependent Setup (FSSDS) has a $t_{i j}$ processing time, and $n$ jobs $(n=1,2,3, \ldots, i)$ that are processed on the m machine $(m=$ $1,2,3, \ldots j)$. Some FSSDS assumptions are (1) the sequence of $n$ jobs $(n=1,2,3, \ldots, j)$ done on each $m$ of machines $(m=1,2,3, \ldots, i)$ is the same. (2) the processing time for each job is Pij. Pij shows the time of the $i-j o b$ and is done on the $j-$ machine. (3) All machines are available when $t=0$. (4) The setup time depends on the work order, and it is separated from the processing time. (5) the time set up job $i$ to job $i+1$ on machine $\mathrm{j}$ is $S_{i, i+1}$. Furthermore, $S_{i}$ shows the setup time for job $i$ if the job $i$ is the first order job. (6) Each job, when it starts processing to completion, must be in order and must not be interrupted. 
(7) Each machine starts at time $=0$ and finishes when the last job on each machine is finished (each machine that stops independently of other machines). The notation used in scheduling carbon emissions minimization is as follows:

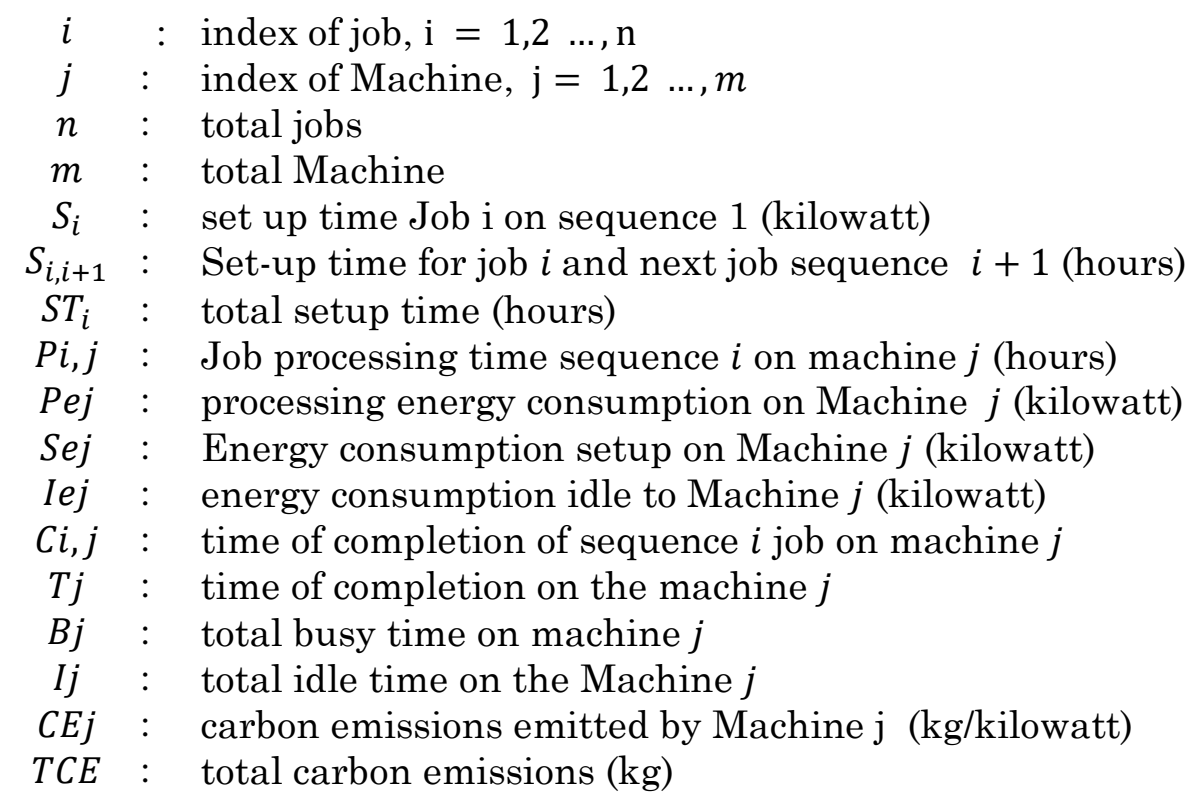

The purpose of this model is to minimize carbon emissions (TCE) [31]. Following is the FSSDS formula for minimizing the total carbon emissions:

Minimize TCE

Subject to

$$
\begin{aligned}
& C_{1,1}=P_{1,1}+S_{1} \\
& C_{1, j}=\max \left(C_{1, j-1}, S_{1}\right)+P_{1, j}, \quad j=2 \ldots m \\
& C_{i, 1}=C_{i-1,1}+S_{i, i+1}+P_{i, 1}, \quad i=2 . . n \\
& C_{i, j}=\max \left(C_{i, j-1}, S_{i, i+1}+C_{i-1, j}\right)+P_{i, j}, i=2 \ldots n, \quad j=2 \ldots m \\
& B j=\sum_{j=1}^{n} P i j \\
& S T j=S i+\sum_{i=2}^{m} S_{i, i+1}, \quad j=1 \ldots m \\
& I j=T j-(B j+S T j), \quad j=1 \ldots m \\
& T C E=\sum_{j=1}^{n}(\text { Bj.Pej.CEj+STj.Sej.CEj+Ij.Iej.CEj) }
\end{aligned}
$$

Equation (1) formulates the objective of minimizing carbon emissions. Equation (2) illustrates the formula for completing job sequence 1 in machine 1. Equation (3) shows the completion time of job sequence one on machines 2 to j. Equation (4) describes the completion time of a sequence $i$ job on machine 1. Equation (5) illustrates the completion time of a sequence $i$ job machine $j$. Equation (6) explains the machines busy time $j$. Equation (7) illustrates the total setup time on machine j. Equation (8) shows the total idle time on machine j. Equation (9) illustrates the formula for calculating total carbon emissions.

\subsection{Hybrid Sine Cosine Algorithm (HSCA) algorithm proposed}

We proposed Hybrid Sine Cosine Algorithm (HSCA) for minimizing total carbon emissions in the FSSDS problem. The HSCA algorithm also has the characteristics to solve scheduling. We called this algorithm the Hybrid Sine Cosine Algorithm (HSCA). We added 
the NEH algorithm to improve HSCA performance. In this article, the NEH algorithm replaced one search agent in the SCA. There are four steps in the HSCA algorithm: initializing positions for search agents, applying LRV for sequence, changing one search agent position using the NEH algorithm, and evaluating SCA. Pseudo-code proposed algorithm is presented in Algorithm 1.

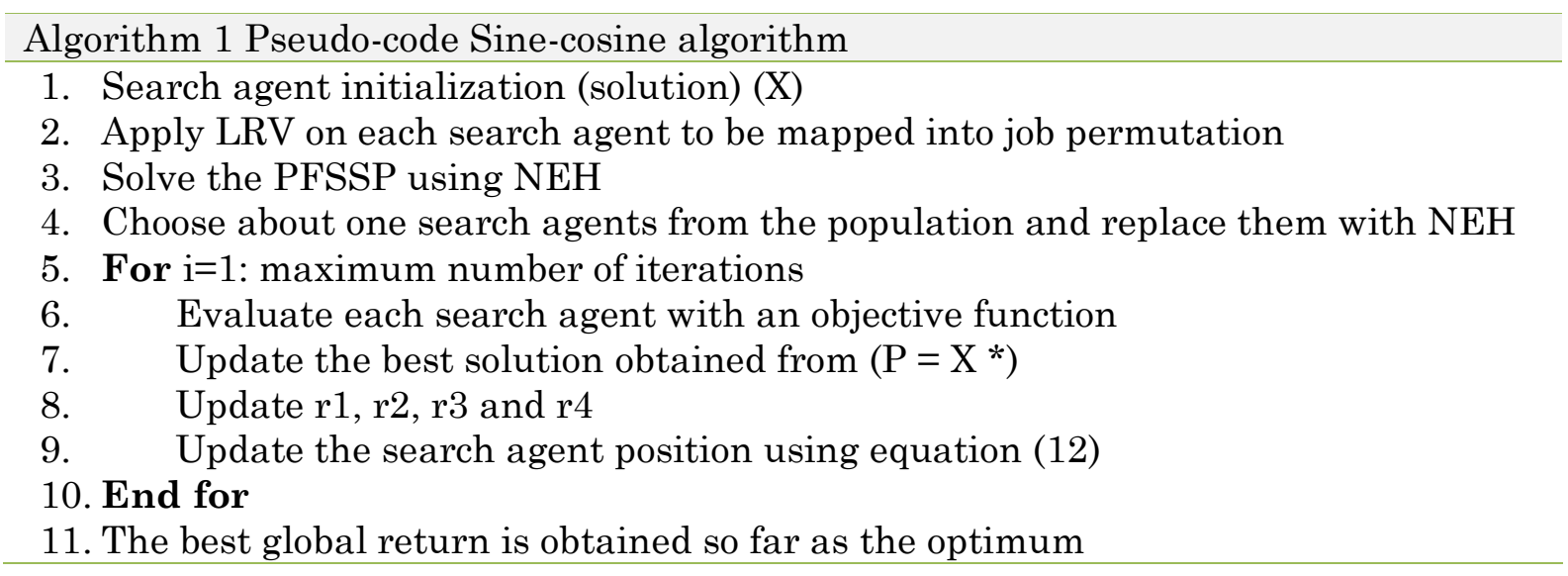

\subsubsection{Nawaz Enscore Ham (NEH) Algorithm}

Nawaz Enscore Ham (NEH) is a practical heuristic algorithm for FSSP cases. The workings of the NEH method are jobs with the most significant total processing time given top priority to be carried out [12]. Initialize NEH job sequences descending based on the total processing time of each job. Furthermore, each job position's best order is determined (see Algorithm 2) [32].

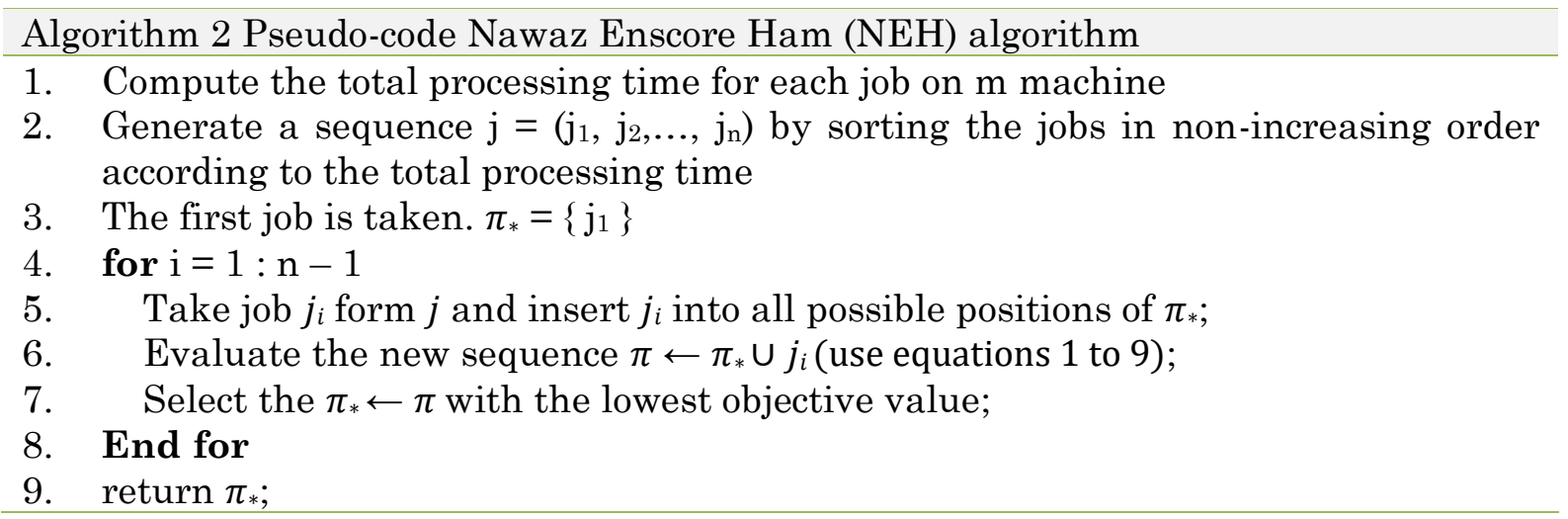

\subsubsection{Initialize Search Agent position}

The initial position of the search agent is generated randomly. Agent search position based on upper bound and lower bound. It must be ensured that there is no similar loop in the initialization of the search agent position. Fig. 1 illustrates the position of the search agent. The search agent position is a matrix.

\subsubsection{Apply Large Rank Value (LRV)}

We proposed a ranking order for search agents using Large Rank Value (LRV). LRV procedure is sorting from the largest to the smallest value. Fig. 2 illustrates an illustration of how the LRV works. 


$\left[\begin{array}{lll}0,71 & 0,58 & 0,62 \\ 0,39 & 0,95 & 0,46\end{array}\right]\left[\begin{array}{lll}0,71 & 0,58 & 0,58 \\ 0,39 & 0,95 & 0,46\end{array}\right]$

Correct Position Wrong Position

Fig. 1. Illustrates Initialization

\begin{tabular}{|c|c|c|}
\hline 0,58 & 0,32 & 0,86 \\
\hline \multicolumn{3}{|c|}{$\downarrow$} \\
J1 & J2 & J3 \\
\hline 2 & 3 & 1 \\
\hline
\end{tabular}

Fig. 2. Illustrates LRV

\subsubsection{Sine-Cosine Algorithm (SCA)}

We proposed a Hybrid Sine-cosine algorithm that has been proposed by Mirjalili [28]. The basic principle of the SCA algorithm is to combine random solutions with a high degree of randomness to find the optimal solution from the search space. The Sine and Cosine effects on formulated in Equations (10) and (11).

$$
\begin{gathered}
X_{i}^{t+1}=X_{i}^{t}+r_{1} \cdot \sin \left(r_{2}\right) \cdot\left|r_{3} P_{i}^{t}-X_{i}^{t}\right| \\
X_{i}^{t+1}=X_{i}^{t}+r_{1} \cdot \cos \left(r_{2}\right) \cdot\left|r_{3} P_{i}^{t}-X_{i j}^{t}\right|
\end{gathered}
$$

$X_{i}^{t}$ shows the position of the solution during the $i-t h$ dimension in the $t-$ iteration. $r 1 / r 2 / r 3$ describe random numbers. $P_{i}$ is the position of the destination point in the $i-t h$ dimension. Moreover, II show absolute value. These two equations are combined as in equation (12).

$$
X_{i}^{t+1}=\left\{\begin{array}{l}
X_{i}^{t}+\eta_{1} \cdot \sin \left(r_{2}\right) \cdot\left|r_{3} P_{i}^{t}-X_{i}^{t}\right|, r_{4}<0.5 \\
X_{i}^{t}+r_{1} \cdot \cos \left(r_{2}\right) \cdot\left|r_{3} P_{i}^{t}-X_{i}^{t}\right|, r_{4} \geq 0.5
\end{array}\right.
$$

Equation (12) shows that there are four main parameters in SCA. These are $r 1, r 2$, $r 3$, and $r 4$. The parameter $r 1$ determines the next position area in the form of space between the solution and the destination. The parameter $r 2$ determines how far the movement must go in or out of the destination. The $r 3$ parameter is a random weight. Parameter $r 4$ shows the random number of transitions between the sine and cosine components in Equation (12). Random location is achieved by defining the number $r 2$ in the range $[0,2 \pi]$ in equation (12). This algorithm can balance exploration and exploitation to find the optimal global solution. To balance the exploration and exploitation phase, sines and cosines in Equations (10) through (12) are changed adaptively using equation (13). $t$ is the current iteration. $T$ indicates the maximum number of iterations. Moreover, $a$ is a constant. General steps of the SCA Algorithm are presented in Algorithm 3.

$$
r_{1}=a-t \frac{a}{T}
$$

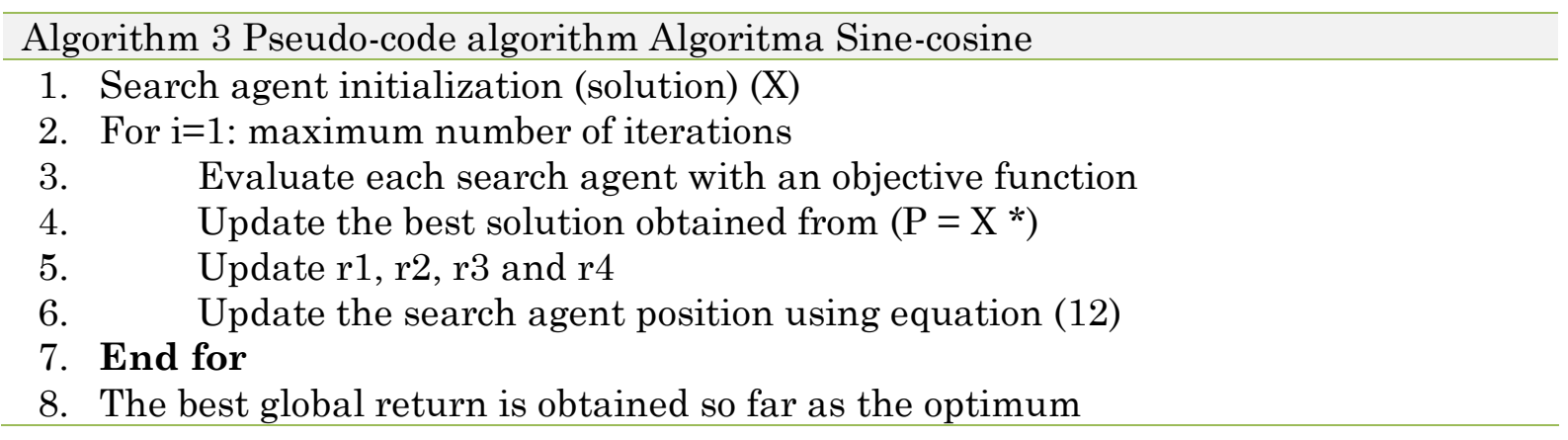




\subsection{Experiment Procedures}

This study used seven variations of the job. Furthermore, this study used two various machines. The total experimental environment in this study was 14 . Generation of processing time, job set-up time in the first sequence, and set-up time for sequences from job $i$ to job $i+1$ were uniform $(10.50)$, uniform $(1,10)$, and uniform $(1,10)$. The value of the generation of uniform distributions Process energy consumption, Set up energy consumption, and idle engine energy consumption was (5.10), (1.2), and (1.3), respectively. Carbon emissions from each engine were obtained with uniform parameter values (0.1).

In the parameter experiment, the parameters used the experiments are population and iteration. The HSCA population factor consisted of 3 levels: population 10, 50, and 100. Iteration factor consisted of 5 levels as 10, 50, 100, 200, and 500. For every data, there were 15 experiments performed. The study had 14 different experimental environments. Thus, the experiment was carried out as much as 210 times the treatment. To test the effectiveness of the algorithm, the study conducted a comparison with several algorithms. The algorithm chosen for comparison was simulated annealing and genetic algorithm. The algorithm was a popular algorithm at the moment. HSCA parameters used are 100 populations and 500 iterations. Comparative testing used 100 job problems and 16 machines. The problem was repeated 20 times. The comparative test used an independent sample t-test. Numerical tests were carried out in the Matlab R16 software on a Windows 8.1 AMD 4 x86-64 4 GB processor. A variety of population, job, machine, and iterations are used to find the most optimal possibilities for minimizing carbon emotions.

\section{Result and Discussions}

This section explains the effectiveness of the proposed algorithm, the results of total carbon emissions, and the computational time of each experiment. We reported the results of developing the SCA algorithm to solve optimization problems. The results of experiments conducted on the Matlab application produce total carbon emissions and computational time according to population, number of jobs, number of machines, and number of iterations.

\subsection{Results HSCA parameters toward carbon emissions}

Table 1 is a recapitulation of the results of the HSCA experiment on carbon emissions. Based on the results of the experiment, there are several findings from the results of the experiment. The higher the job and when the number of machines is the same, the more significant carbon emissions are produced. The higher the number of machines and when the number of jobs is the same, the carbon emissions produced will be even higher. The higher the population used, the smaller the carbon emissions produced. Thus, carbon emissions are influenced by population. If the iteration is used, the more significant the carbon emission value will be smaller. In small jobs, the parameters that should be used are small populations and small iterations. Furthermore, in large jobs, the parameters that should be used are large populations and significant iterations.

\subsection{Testing HSCA parameters for computational time}

Table 2 shows the recapitulation of computational time for various possible populations, jobs, machines, and the number of iterations. The findings of several 
experiments are as follows. The higher the job used, the greater the computational time required. The higher the number of machines used, the greater the required computing time. The higher the population, the greater the computational time. Thus, computing time is influenced by the population. If the iteration gets high, then the computing time also gets high. Thus, computing time is affected by the number of iterations.

Table 1. Results of experiments on carbon emissions (kg)

\begin{tabular}{|c|c|c|c|c|c|c|c|}
\hline \multirow{2}{*}{ Population } & \multirow{2}{*}{ Job } & \multirow{2}{*}{ Machine } & \multicolumn{5}{|c|}{ Iterations } \\
\hline & & & 10 & 50 & 100 & 200 & 500 \\
\hline \multirow{14}{*}{10} & 5 & 4 & 397.2672 & 397.2672 & 397.2672 & 397.2672 & 397.2672 \\
\hline & 5 & 16 & 12327 & 12283 & 12283 & 12283 & 12283 \\
\hline & 10 & 4 & 6429.8 & 6398.3 & 6403.2 & 6398.5 & 6394.5 \\
\hline & 10 & 16 & 25684 & 25570 & 25406 & 25328 & 25442 \\
\hline & 20 & 4 & 5592.5 & 5592.6 & 5588.3 & 5588.3 & 5587.8 \\
\hline & 20 & 16 & 41821 & 41527 & 41397 & 41449 & 41425 \\
\hline & 40 & 4 & 17476 & 17471 & 17468 & 17453 & 17455 \\
\hline & 40 & 16 & 99262 & 99223 & 99100 & 99050 & 98976 \\
\hline & 60 & 4 & 33861 & 33826 & 33770 & 33814 & 33796 \\
\hline & 60 & 16 & 109200 & 10911 & 108940 & 108770 & 108840 \\
\hline & 80 & 4 & 57749 & 57776 & 57692 & 57657 & 57690 \\
\hline & 80 & 16 & 189640 & 18964 & 189500 & 189310 & 189270 \\
\hline & 100 & 4 & 63490 & 63450 & 63466 & 63440 & 63446 \\
\hline & 100 & 16 & 189070 & 18907 & 188590 & 188660 & 188450 \\
\hline \multirow{14}{*}{50} & 5 & 4 & 397.267 & 397.267 & 397.267 & 397.2672 & 397.267 \\
\hline & 5 & 16 & 12283 & 12283 & 12283 & 12283 & 12283 \\
\hline & 10 & 4 & 6410.9 & 6403.2 & 6395.6 & 6394.5 & 6394.5 \\
\hline & 10 & 16 & 25497 & 25518 & 25389 & 25311 & 25347 \\
\hline & 20 & 4 & 5588.5 & 5589.2 & 5587.6 & 5580.1 & 5582.8 \\
\hline & 20 & 16 & 41498 & 41406 & 41404 & 41378 & 41303 \\
\hline & 40 & 4 & 17471 & 17468 & 17459 & 17459 & 17449 \\
\hline & 40 & 16 & 99231 & 99075 & 99008 & 98931 & 98871 \\
\hline & 60 & 4 & 33844 & 33814 & 33801 & 33776 & 33759 \\
\hline & 60 & 16 & 108950 & 108910 & 108730 & 108860 & 108550 \\
\hline & 80 & 4 & 57758 & 57692 & 57675 & 57678 & 57663 \\
\hline & 80 & 16 & 189570 & 189290 & 189150 & 189270 & 189290 \\
\hline & 100 & 4 & 63469 & 63470 & 63446 & 63427 & 63425 \\
\hline & 100 & 16 & 188800 & 188750 & 188570 & 188710 & 188230 \\
\hline \multirow{14}{*}{100} & 5 & 4 & 397.267 & 397.267 & 397.267 & 397.267 & 397.267 \\
\hline & 5 & 16 & 12283 & 12283 & 12283 & 12283 & 12283 \\
\hline & 10 & 4 & 6396 & 6392.4 & 6392.1 & 6394.5 & 6391.2 \\
\hline & 10 & 16 & 25466 & 25329 & 25423 & 25393 & 25370 \\
\hline & 20 & 4 & 5583.9 & 5585.2 & 5582.6 & 5584.8 & 5581.4 \\
\hline & 20 & 16 & 41641 & 41423 & 41359 & 41350 & 41267 \\
\hline & 40 & 4 & 17465 & 17456 & 17460 & 17456 & 17454 \\
\hline & 40 & 16 & 99005 & 98884 & 98949 & 98913 & 98872 \\
\hline & 60 & 4 & 33782 & 33736 & 33773 & 33770 & 33736 \\
\hline & 60 & 16 & 108920 & 108790 & 108810 & 108640 & 108670 \\
\hline & 80 & 4 & 57721 & 57692 & 57676 & 57640 & 57651 \\
\hline & 80 & 16 & 189610 & 189340 & 189320 & 189150 & 188910 \\
\hline & 100 & 4 & 63446 & 63449 & 63418 & 63415 & 63432 \\
\hline & 100 & 16 & 188900 & 188580 & 188340 & 188350 & 188420 \\
\hline
\end{tabular}


Table 2. The results of experiments on computational time (second)

\begin{tabular}{|c|c|c|c|c|c|c|c|}
\hline \multirow{2}{*}{ Population } & \multirow{2}{*}{ Job } & \multirow{2}{*}{ Machine } & \multicolumn{5}{|c|}{ Iteration } \\
\hline & & & 10 & 50 & 100 & 200 & 500 \\
\hline \multirow{14}{*}{10} & 5 & 4 & 0.125 & 0.3906 & 0.375 & 0.6563 & 1.4219 \\
\hline & 5 & 16 & 0.0938 & 0.2188 & 0.4063 & 0.7031 & 1.5469 \\
\hline & 10 & 4 & 0.0625 & 0.25 & 0.3438 & 0.7188 & 1.3906 \\
\hline & 10 & 16 & 0.0938 & 0.2031 & 0.3906 & 0.6875 & 1.6094 \\
\hline & 20 & 4 & 0.125 & 0.3438 & 0.6719 & 0.625 & 1.6563 \\
\hline & 20 & 16 & 0.0938 & 0.2813 & 0.4063 & 0.7188 & 1.8594 \\
\hline & 40 & 4 & 0.0469 & 0.2031 & 0.3594 & 0.6094 & 1.5781 \\
\hline & 40 & 16 & 0.0938 & 0.2969 & 0.4844 & 0.875 & 2.1406 \\
\hline & 60 & 4 & 0.0938 & 0.1875 & 0.4531 & 0.7031 & 1.5 \\
\hline & 60 & 16 & 0.1406 & 0.3281 & 0.5156 & 1.0313 & 2.2969 \\
\hline & 80 & 4 & 0.0781 & 0.2656 & 0.4844 & 0.7656 & 2.0469 \\
\hline & 80 & 16 & 0.125 & 0.3281 & 0.6563 & 1.4844 & 3.1406 \\
\hline & 100 & 4 & 0.125 & 0.4063 & 0.5313 & 0.7656 & 2 \\
\hline & 100 & 16 & 0.1563 & 0.3906 & 0.6875 & 1.3594 & 3.0313 \\
\hline \multirow{14}{*}{50} & 5 & 4 & 0.2813 & 0.7344 & 1.1406 & 2.5313 & 5.3906 \\
\hline & 5 & 16 & 0.2188 & 0.7188 & 1.3438 & 2.5781 & 6.3438 \\
\hline & 10 & 4 & 0.1875 & 0.5781 & 1.0938 & 2.375 & 5.5156 \\
\hline & 10 & 16 & 0.1875 & 0.6875 & 1.3594 & 2.7031 & 6.7656 \\
\hline & 20 & 4 & 0.3281 & 0.75 & 1.2813 & 2.4531 & 5.875 \\
\hline & 20 & 16 & 0.2031 & 0.9531 & 1.75 & 3.0938 & 7.8438 \\
\hline & 40 & 4 & 0.2031 & 0.75 & 1.2969 & 2.5313 & 6.1563 \\
\hline & 40 & 16 & 0.2969 & 0.9375 & 1.8906 & 3.6719 & 9.0625 \\
\hline & 60 & 4 & 0.2344 & 0.7969 & 1.4219 & 2.875 & 6.6875 \\
\hline & 60 & 16 & 0.3125 & 1.1406 & 2.0938 & 4.9688 & 12.4063 \\
\hline & 80 & 4 & 0.2813 & 0.7969 & 1.8281 & 3.6875 & 8.3906 \\
\hline & 80 & 16 & 0.3594 & 1.4531 & 3.1875 & 6.3125 & 14.75 \\
\hline & 100 & 4 & 0.2813 & 0.9375 & 1.6094 & 3.1563 & 7.5781 \\
\hline & 100 & 16 & 0.4063 & 1.4688 & 2.8281 & 5.4219 & 13.2031 \\
\hline \multirow{14}{*}{100} & 5 & 4 & 0.2969 & 1.0781 & 2.375 & 4.1719 & 10.2656 \\
\hline & 5 & 16 & 0.4219 & 1.2656 & 2.4844 & 5.0156 & 12.25 \\
\hline & 10 & 4 & 0.5 & 1.2188 & 2.1875 & 4.5625 & 10.5781 \\
\hline & 10 & 16 & 0.3125 & 1.3281 & 2.6875 & 5.2813 & 13.3438 \\
\hline & 20 & 4 & 0.2969 & 1.1563 & 2.3281 & 4.5156 & 11.1875 \\
\hline & 20 & 16 & 0.4063 & 1.6875 & 3.2344 & 6.6406 & 15.1094 \\
\hline & 40 & 4 & 0.4063 & 1.3125 & 2.5781 & 4.9688 & 12.0781 \\
\hline & 40 & 16 & 0.5469 & 1.9375 & 3.5313 & 7.2344 & 17.6094 \\
\hline & 60 & 4 & 0.3594 & 1.4063 & 2.8906 & 5.3125 & 13.0781 \\
\hline & 60 & 16 & 0.5625 & 2.6875 & 4.6719 & 9.4531 & 22.6563 \\
\hline & 80 & 4 & 0.4219 & 2.0781 & 3.2656 & 6.6875 & 16.4688 \\
\hline & 80 & 16 & 0.6094 & 2.6875 & 6.5469 & 11.0938 & 28.6719 \\
\hline & 100 & 4 & 0.4063 & 1.6563 & 3.0469 & 5.9063 & 14.8906 \\
\hline & 100 & 16 & 0.75 & 2.9219 & 5.5625 & 10.4063 & 26.0938 \\
\hline
\end{tabular}




\subsection{HSCA Testing of Other Algorithms}

Based on the independent sample t-test (Table 3 and Table 4), the SCA algorithm performs better than the $\mathrm{CE}$ and SA algorithms. The average value of carbon SCA emissions produced in the experiment is $200021.50 \mathrm{~kg}$. Furthermore, the CE and SA algorithms produce carbon emissions of $206541.65 \mathrm{~kg}$ and $205451.32 \mathrm{~kg}$. The independent t-test statistic test shows ALO algorithm has a significant difference from the CE and SA algorithms.

Table 3. Descriptive summary of the algorithm comparison

\begin{tabular}{lllllll}
\hline Algorithm & $\begin{array}{l}\text { Number } \\
\text { Experimental }\end{array}$ & $\begin{array}{l}\text { Average Carbon } \\
\text { emission }(\mathrm{kg})\end{array}$ & $\begin{array}{l}\text { Std. } \\
(\mathrm{Kg})\end{array}$ & Deviation & $\begin{array}{l}\text { Std. Error } \\
(\mathrm{Kg})\end{array}$ & Mean \\
\hline SCA & 20 & 200021.50 & 1774.21 & 324.62 & \\
CE & 20 & 206541.65 & 4213.28 & 914.21 & \\
SA & 20 & 205451.32 & 3541.20 & 782.88 & \\
\hline
\end{tabular}

Table 4. Independent t-test results

\begin{tabular}{llll}
\hline Algorithm & t-value & Sig. $(2$-tailed) & Decision \\
\hline SCA-CE & -5.756 & 0.000 & Significant of differences \\
SCA-SA & -7.216 & 0.000 & Significant of differences \\
\hline
\end{tabular}

\section{Conclusion}

The results of the research show that the higher the amount of work, the greater the carbon emissions produced. If the work is significant, the optimal solution is to use a large population and iteration. Moreover, conversely, if the amount of work is small, the optimal solution is to use a small population and iteration. The experimental results show that the HSCA algorithm helps solve FSSDS problems. Suggestions for further research are to improve the algorithm by providing new, more active steps to reduce computational time.

\section{References}

[1] S. Shafiee and E. Topal, "When will fossil fuel reserves be diminished?," Energy Policy, vol. 37, pp. 181-189, 2009. https://doi.org/10.1016/j.enpol.2008.08.016.

[2] K. Aleklett, M. Höök, K. Jakobsson, M. Lardelli, S. Snowden, and B. Söderbergh, "The Peak of the Oil Age - Analyzing the world oil production Reference Scenario in World Energy Outlook 2008," Energy Policy, vol. 38, pp. 1398-1414, 2010. https://doi.org/10.1016/j.enpol.2009.11.021.

[3] T. Simunic, L. Benini, and G. D. Micheli, "Energy-efficient design of batterypowered embedded systems," IEEE Transactions on Very Large Scale Integration (VLSI) Systems, vol. 9, pp. 15-28, 2001. https://doi.org/10.1109/92.920814.

[4] V. Swaminathan and K. Chakrabarty, "Energy-conscious, deterministic I/O device scheduling in hard real-time systems," IEEE Transactions on Computer-Aided Design of Integrated Circuits and Systems, vol. 22, pp. 847-858, 2003. https://doi.org/10.1109/TCAD.2003.814245.

[5] T. Gutowski, C. Murphy, D. Allen, D. Bauer, B. Bras, T. Piwonka, et al., "Environmentally benign manufacturing: Observations from Japan, Europe and 
the United States," Journal of Cleaner Production, vol. 13, pp. 1-17, 2005. https://doi.org/10.1016/j.jclepro.2003.10.004.

[6] S. Harto, A. K. Garside, and D. M. Utama, "Penjadwalan Produksi Menggunakan Algoritma Jadwal Non Delay Untuk Meminimalkan Makespan (studi kasus di CV. Bima Mebel)," Spektrum Industri, vol. 14, pp. 79-88, 2015. http://journal.uad.ac.id/index.php/Spektrum/article/view/3706.

[7] D. M. Utama, "Analisa Perbandingan Penggunaan Aturan Prioritas Penjadwalan Pada Penjadwalan Non Delay N Job 5 Machine," Prosiding SENTRA (Seminar Teknologi dan Rekayasa), vol. 2, pp. 19-23, $2017 . \quad$ http://researchreport.umm.ac.id/index.php/research-report/article/view/1180.

[8] I. Masudin, D. M. Utama, and F. Susastro, "Penjadwalan Flowshop Menggunakan Algoritma Nawaz Enscore Ham," Jurnal Ilmiah Teknik Industri, vol. 13, pp. 5459, 2014. https://doi.org/10.23917/jiti.v13i1.321.

[9] I. Benkalai, D. Rebaine, C. Gagné, and P. Baptiste, "The migrating birds optimization metaheuristic for the permutation flow shop with sequence dependent setup times," IFAC-PapersOnLine, vol. 49, pp. 408-413, 2016. https://doi.org/10.1016/j.ifacol.2016.07.640.

[10] H. G. Campbell, R. A. Dudek, and M. L. Smith, "A heuristic algorithm for the n job, $\mathrm{m}$ machine sequencing problem," Management science, vol. 16, pp. B-630-B-637, 1970. https://doi.org/10.1287/mnsc.16.10.B630.

[11] D. M. Utama, "Algoritma LPT-Branch and Bound Pada Penjadwalan Flexible Flowshop untuk Meminimasi Makespan," PROZIMA (Productivity, Optimization and Manufacturing System Engineering), vol. 2, pp. 20-26, 2018. http://ojs.umsida.ac.id/index.php/prozima/article/view/1527.

[12] M. Nawaz, E. E. Enscore, and I. Ham, "A heuristic algorithm for the m-machine, n-job flow-shop sequencing problem," Omega, vol. 11, pp. 91-95, 1983. https://doi.org/10.1016/0305-0483(83)90088-9.

[13] M. Husen, I. Masudin, and D. Utama, "Penjadwalan job shop statik dengan metode simulated annealing untuk meminimasi waktu makespan," Spektrum Industri, vol. 13, pp. 115-228, 2015. http://dx.doi.org/10.12928/si.v13i2.2689.

[14] M. Firdaus, I. Masudin, and D. M. Utama, "Penjadwalan Flowshop Dengan Menggunakan Simulated Annealing," Spektrum Industri, vol. 13, pp. 27-40, 2015. http://dx.doi.org/10.12928/si.v13i1.1836.

[15] R. Nasution, A. K. Garside, and D. M. Utama, "Penjadwalan Job Shop Dengan Pendekatan Algoritma Artificial Immune System," Jurnal Teknik Industri, vol. 18, pp. 29-42, 2017. https://doi.org/10.22219/JTIUMM.Vol18.No1.29-42.

[16] V. Riahi, M. A. H. Newton, K. Su, and A. Sattar, "Constraint guided accelerated search for mixed blocking permutation flowshop scheduling," Computers \& Operations Research, vol. 102, pp. 102-120, 2019. https://doi.org/10.1016/j.cor.2018.10.003.

[17] C.-Y. Cheng, K.-C. Ying, H.-H. Chen, and J.-X. Lin, "Optimization algorithms for proportionate flowshop scheduling problems with variable maintenance activities," Computers \& Industrial Engineering, vol. 117, pp. 164-170, 2018. https://doi.org/10.1016/j.cie.2018.01.027.

[18] V. Riahi, M. Khorramizadeh, M. A. Hakim Newton, and A. Sattar, "Scatter search for mixed blocking flowshop scheduling," Expert Systems with Applications, vol. 79, pp. 20-32, 2017. https://doi.org/10.1016/j.eswa.2017.02.027.

[19] N. Karimi and H. Davoudpour, "Multi-objective colonial competitive algorithm for hybrid flowshop problem," Applied Soft Computing, vol. 49, pp. 725-733, 2016. https://doi.org/10.1016/j.asoc.2016.06.034. 
[20] S. Hatami, L. Calvet, V. Fernández-Viagas, J. M. Framiñán, and A. A. Juan, "A simheuristic algorithm to set up starting times in the stochastic parallel flowshop problem," Simulation Modelling Practice and Theory, vol. 86, pp. 55-71, 2018. https://doi.org/10.1016/j.simpat.2018.04.005.

[21] D. M. Utama, "Pengembangan Algoritma NEH Dan CDS Untuk Meminimasi Consumption Energy Pada Penjadwalan Flow Shop," Prosiding SENTRA (Seminar Teknologi dan Rekayasa), vol. 4, pp. 47-54, 2018. http://researchreport.umm.ac.id/index.php/sentra/article/view/2309.

[22] Q. Liu, M. Zhan, F. O. Chekem, X. Shao, B. Ying, and J. W. Sutherland, "A hybrid fruit fly algorithm for solving flexible job-shop scheduling to reduce manufacturing carbon footprint," Journal of Cleaner Production, vol. 168, pp. 668-678, 2017. https://doi.org/10.1016/j.jclepro.2017.09.037.

[23] Z. Zeng, M. Hong, Y. Man, J. Li, Y. Zhang, and H. Liu, "Multi-object optimization of flexible flow shop scheduling with batch process - Consideration total electricity consumption and material wastage," Journal of Cleaner Production, vol. 183, pp. 925-939, 2018. https://doi.org/10.1016/j.jclepro.2018.02.224.

[24] D. Tang, M. Dai, M. A. Salido, and A. Giret, "Energy-efficient dynamic scheduling for a flexible flow shop using an improved particle swarm optimization," Computers in Industry, vol. 81, pp. 82-95, 2016. https://doi.org/10.1016/j.compind.2015.10.001.

[25] H. Piroozfard, K. Y. Wong, and W. P. Wong, "Minimizing total carbon footprint and total late work criterion in flexible job shop scheduling by using an improved multiobjective genetic algorithm," Resources, Conservation and Recycling, vol. 128, pp. 267-283, 2018. https://doi.org/10.1016/j.resconrec.2016.12.001.

[26] X. Li, W. Li, X. Cai, and F. He, "A hybrid optimization approach for sustainable process planning and scheduling," Integrated Computer-Aided Engineering, vol. 22, pp. 311-326, 2015. https://doi.org/10.3233/ICA-150492

[27] X. Wu and A. Che, "A memetic differential evolution algorithm for energy-efficient parallel machine scheduling," Omega, vol. 82, pp. 155-165, 2019. https://doi.org/10.1016/j.omega.2018.01.001.

[28] J. Batista Abikarram, K. McConky, and R. Proano, "Energy cost minimization for unrelated parallel machine scheduling under real time and demand charge pricing," Journal of Cleaner Production, vol. 208, pp. 232-242, 2019. https://doi.org/10.1016/j.jclepro.2018.10.048.

[29] M. Tan, Y. Chen, Y.-x. Su, S.-h. Li, and H. Li, "Integrated optimization model for industrial self-generation and load scheduling with tradable carbon emission permits," Journal of Cleaner Production, vol. 210, pp. 1289-1300, 2019. https://doi.org/10.1016/j.jclepro.2018.11.005.

[30] S. Mirjalili, "SCA: A Sine Cosine Algorithm for solving optimization problems," Knowledge-Based Systems, vol. 96, pp. 120-133, 2016. https://doi.org/10.1016/j.knosys.2015.12.022.

[31] G. I. Galinato and J. K. Yoder, "An integrated tax-subsidy policy for carbon emission reduction," Resource and Energy Economics, vol. 32, pp. 310-326, 2010. https://doi.org/10.1016/j.reseneeco.2009.10.001.

[32] Y. B. Park, C. D. Pegden, and E. E. Enscore, "A survey and evaluation of static flowshop scheduling heuristics," International Journal of Production Research, vol. 22, pp. 127-141, 1984. https://doi.org/10.1080/00207548408942436. 